\title{
Multimedia Interfaces for BSL Using Lip Readers
}

\author{
Faramaz Eyasim Joumun ${ }^{1}$, Paul Gnanayutham ${ }^{2}$ and Jennifer George ${ }^{3}$ \\ ${ }^{1}$ Researcher \\ ${ }^{2}$ Department of Computing, University of Portsmouth, Buckingham Building, Lion Terrace, \\ Portsmouth PO1 3HE, United Kingdom \\ ${ }^{3}$ SAE Institute, United House, North Road, London, N7 9DP, United Kingdom \\ \{fara142@hotmail.com,jennifer.george@sae.edu, paul.gnanayutham@port.ac.uk\}
}

\begin{abstract}
This paper deals with mainly the profoundly deaf people who are beginning to learn the British Sign Language (BSL) as their first language for communication. These beginners could be children, teenagers or even adults who have hearing problems. There are already quite a few BSL learning websites and Lip Reading software available on the market. However, there is no such software that associates the two associated problems although there might be BSL users who can benefit from Lip Reading. This could help them not only for communication but also enable them to interact more with people with a normal hearing range, who as a matter of fact, form a major part of the society we live in. The artifact aims to be run on most computers making it easier for people to access and use it without the need for any additional costly features.
\end{abstract}

\section{Rationale}

The main reason for developing a software program to assist BSL users to learn Lip Reading was initiated by sibling of the first author who was born deaf and currently a proficient BSL user. She is currently 15 and attends a specialised educational institution in London. Although she has qualified teachers for teaching the main subjects, a few subjects like Science and Art have to be taught in different mainstream schools. This is due to the lack of resources such as science laboratories. The subjects she learns at these schools are taught by teachers without BSL qualification and therefore require an interpreter for the deaf pupils. This procedure is exhausting, since these children have to follow two teachers simultaneously to understand the lessons. This school offers Lip Reading classes for the students once every week. These classes are very limited and the learners are unable to practice any of the lessons on their own time. They neither have any books nor resources to do so. Hence, they are not trained enough to Lip Read in real life. Another major problem faced by the deaf in general is their feeling left out within a group of normal-hearing people because of the communication and language barrier. It's not realistic to get every single normal-hearing person to learn BSL and communicate using the sign language on a regular basis. 
If deaf people could lip read efficiently, problems like the ones faced by students such as the researcher's sister, who has to follow two teachers at the same time for one lesson and also being unable to integrate with the majority of other students, could be reduced considerably. Overall, the deaf people as well as the hearing people will benefit from this developed software, since this software can be used as a teaching tool for both deaf learners and teachers in the main stream schools who do not know the BSL language. The originality of the project lies in the fact that the application developed links Lip Reading to BSL. Since deaf people use BSL as their first language for communication, Lip Reading is most helpful for them. It is useful to associate these two areas to make the learning process more effective and appropriate for this group of disabled personnel.

\section{Introduction}

There are Lip Reading courses available at various educational institutions in the UK, especially through organisations for the deaf people community. The Lip Reading students are required to attend classes and interact with their teachers, either on a oneto-one basis or as a group with the other students. Despite having the right tutoring in their subject, the students may find it quite hard to review their lessons on their own outside the classes. This is because the only resources available for them to do this may be books and handouts that have been provided by teachers. As a result of this, the Lip Reading students depend on their teachers or other Lip Reading students to practice what they have learnt. BSL users with the ability to Lip Read are a very limited group in our society. This means that it is very difficult for the Lip reading students to get help from family or friends outside the deaf community. Technology is an integral part of our life and the profoundly deaf people can make use of it as efficiently as, if not better, than anybody else. Therefore, it will indeed be beneficial to use technology to assist the BSL users to learn Lip Reading.

The main aim of this research is to encourage Lip Reading within the deaf community, more specifically for BSL users, by providing them with a simple and easy-to-use aid that can be utilized by beginners. Literature search was carried out in deafness as a disability and the use of BSL as a language to communicate within the deaf people community and Lip Reading, by interacting with the students, teachers and any other individuals who could provide useful information relevant to the this project. The information to determine the specific requirements has been analysed. Similar products or other products related to deafness, BSL or Lip reading have been explored. After identifying exactly what this developed application should do, it was designed, implemented and evaluated with two deaf participants.

Deafness refers to a hearing impairment or loss that affects people's ability for the perception of sound in general. As a result, the deaf personnel struggle or cannot communicate verbally. There is no age limit associated to deafness. Babies can be born with a hearing impairment just as adults can become deaf after an accident or illness. Deafness can be caused by various factors resulting in any kind of damage or disruption to any part of the hearing system. These conditions can be temporary ones like earwax, infections or foreign body obstructions that may block the ear canal. 


\begin{tabular}{|c|c|}
\hline Cause & Definition \\
\hline Age & $\begin{array}{l}\text { People are likely to have a deterioration or loss of hearing as they } \\
\text { grow older. }\end{array}$ \\
\hline Noise & $\begin{array}{l}\text { Prolonged exposure to excessive noise can gradually cause hearing } \\
\text { loss in the long run. }\end{array}$ \\
\hline \multirow{5}{*}{$\begin{array}{l}\text { Other Ear } \\
\text { Problems }\end{array}$} & Obstructions like ear wax that block the ear canal. \\
\hline & $\begin{array}{l}\text { Inflammation caused by viral or bacterial infection, like Otitis } \\
\text { media (also known as 'glue ear'). }\end{array}$ \\
\hline & $\begin{array}{l}\text { The abnormal growth of bone in the middle ear, which prevents the } \\
\text { ear from functioning properly. This condition is known as } \\
\text { 'Otosclerosis'. }\end{array}$ \\
\hline & Damaged 'Ossicles', which are tiny boned found in the middle ear. \\
\hline & Perforated Eardrums. \\
\hline Genetics & Through heredity and inheritance. \\
\hline
\end{tabular}

Table 1. - Causes of deafness

(http://www.rnid.org.uk/information resources/aboutdeafness/causes/other ear problems/)

\begin{tabular}{|l|l|c|}
\hline Deafness Level & \multicolumn{1}{|c|}{ Difficulty Caused } & $\begin{array}{l}\text { Quietest Sound } \\
\text { (In decibels) }\end{array}$ \\
\hline Mild & $\begin{array}{l}\text { Speech, especially in a noisy } \\
\text { environment. }\end{array}$ & 25 to 39 \\
\hline Moderate & Speech, without a Hearing Aid. & 40 to 69 \\
\hline Severe & $\begin{array}{l}\text { Unable to communicate verbally. } \\
\text { Rely on Lip Reading Or British } \\
\text { Sign Language (BSL) }\end{array}$ & 70 to 94 \\
\hline Profound & $\begin{array}{l}\text { Unable to communicate verbally. } \\
\text { Rely on Lip Reading Or British } \\
\text { Sign Language (BSL) }\end{array}$ & 95 or higher \\
\hline
\end{tabular}

Table 2. - Levels of deafness

(http://www.rnid.org.uk/information_resources/aboutdeafness/meaning_of_deafness/)

Other permanent circumstances may be the outcome of inherited conditions like for instance having deaf parents, infection that affects women during their pregnancy putting their babies at risk to being born deaf or head injury. According to the RNID [1] the main causes for deafness can be categorised as described in Table 1. There are 
various levels of deafness namely, 'Mild', 'Moderate', 'Severe' and 'Profound' based on the quietest sound they can hear. These levels have been summarised and compared in Table 2.

The British Sign Language (BSL) is widely used by the deaf people in the United Kingdom. In fact, BSL is their first language for communicating both within and outside the deaf community. Wang and his team [2] describe sign language as the primary model of communication among the hearing impaired. It is a visual language that utilises the hand and arm together with facial expressions and lip movements. The recognition of sign language aims to provide a competent and precise method of interpreting sign language into text or speech for others to understand.

Waters and his team [3] describe fingerspelling as a manual encoding of the written language that can be used by people using sign language to fill lexical gaps. BSL users employ a two-hand fingerspelling that includes 26 hand arrangements based on the 26 letters of the Roman alphabet. Hearing people are able to spell unfamiliar words by uttering the alphabets that make up the words. Similarly, deaf people utilise the manual alphabets to "spell-out" unfamiliar words. Thus, fingerspelling encodes the writing structure of a language.

Lip Reading, also referred to as Speechreading, is a method of identifying words and/or alphabets by visually translating lip, face and tongue movements to decipher communication from other people. Lay and his team [4] state that Lip Reading is used on a regular basis by the normal-hearing, especially in noisy environments, and also the hearing impaired even though it is not entirely reliable and accurate. Apart from using hearing aids, the hearing impaired and deaf people will find learning Lip Reading essentially useful to improve their communication with other people. Using hearing aids or lip recognition to assist them in communication, the hearing impaired recognise $65 \%$ of the words. On the other hand, if they use hearing aids and Lip Reading simultaneously, the recognition rate of these words raise to $90 \%$.

Bauman [5] said that during normal speech about 13 to 15 speech movements are made per second but the human eyes can pick up only 8 or 9 of these movements. Many English words bear the same movements on the speaker's lips despite having a different sound. These words are known as homophenes. This means that one is unable to distinguish the homophenes unless they can hear the sounds. An example is 'Queen' and 'White'. $10 \%$ of the population have lip movements that are totally impossible to Lip Read while others are simply unable to Speechread. Statistics show that only $23 \%$ of the hearing impaired are able to Speechread effectively. It has also been proven that women are better Speechreaders compared to men. Another drawback of Lip Reading is the fact that the process can be very tiring, making it very hard to have a smooth and easy conversation. All these facts make Lip Reading or Speechreading impossible to be a perfect method of deciphering words.

However, these limitations can be handled by employing measures like requesting the speaker to talk slowly or allow adequate pauses between words. It also helps to make the lip reader aware of the context and subject of discussion beforehand. 


\section{Methodology}

The spiral methodology was used for the development for the artifact developed for this research. The Spiral methodology is quite similar to the Waterfall methodology but also allows additional concepts like prototyping and iteration to take place. It also requires documentation to be presented at each stage during the project life cycle. The choice of the Spiral methodology was justified by the fact that the project dealt with a group, termed 'Deaf community using BSL as their first language'. Due to user frustration, prototypes were tested with normal hearing participants prior to being tested with the deaf people. This meant that the stages need to be re-iterated a number of times. The Spiral methodology met these requirements appropriately.

\section{Design and Development}

Both technical and usability needs were considered and the artefact was tested continuously using able and disabled users. The interface consisted of a welcome screen, the personalisation screen, the options screen, the lip movement screens and the help screen (Figures 1 and 2). Starting from the welcome screen, which has an extremely simple layout, the users have the option to click on a 'Personalise Application Settings' button that will allow them to select a specific:

Text Font

Text Size

Text Style

Text Colour

Background Colour

Once they have changed these settings they should be able to save these new settings and carry on using the application with the new changes being effective.

The Options screen is the main screen that gives the users an opportunity to select one among the three options available for them to see the lip movements. The user will be able to use the application by selecting OPTION 1 - Lip Movements through Alphabets. Similarly, deaf people who are more comfortable with BSL may be prefer OPTION 2 - Lip Movements through BSL. OPTION 3 - Lip Movements through Alphabets and BSL allows the users to combine both OPTION 1 and OPTION 2 to the Lip Movements. 


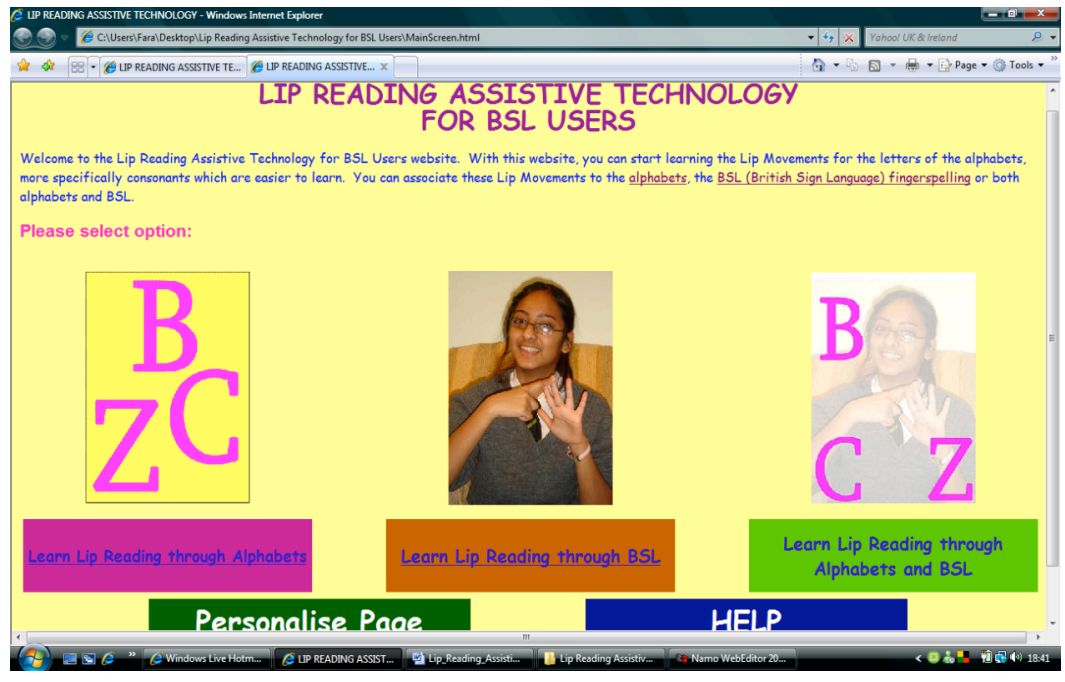

Fig. 1. - Options page

Similarly to the 'Personalise Application Settings' button, the 'Help' button is included at a consistent spot on all the screens of the software. When clicked, the 'Help' button brings up a very simple and concise screen that will allow the users to get some kind of assistance on how they can make use of the application more effectively.

\section{$5 \quad$ Testing}

After two students with hearing impairment used the artefact, qualitative and quantitative feedback was obtained. They were questioned on whether they liked the artefact, whether they wanted to use it again, what score they would rate it in a scale of 1-10 and if there was anything they didn't like about it. Their reply was rather positive as they said they did like the website, they would like to use it again and rated it as 8 and 6 respectively.

The meetings with the students were not planned and were informal. Also, the participants were rather shy and were a bit hesitant to answer questions directly. The fact that there was no interpreter present, again because the meeting was not planned, the communication was rather difficult because they mainly use BSL to communicate and the researchers were not proficient at BSL. Overall they were satisfied with the artifact and admitted that it was the first time they had encountered such a product. 


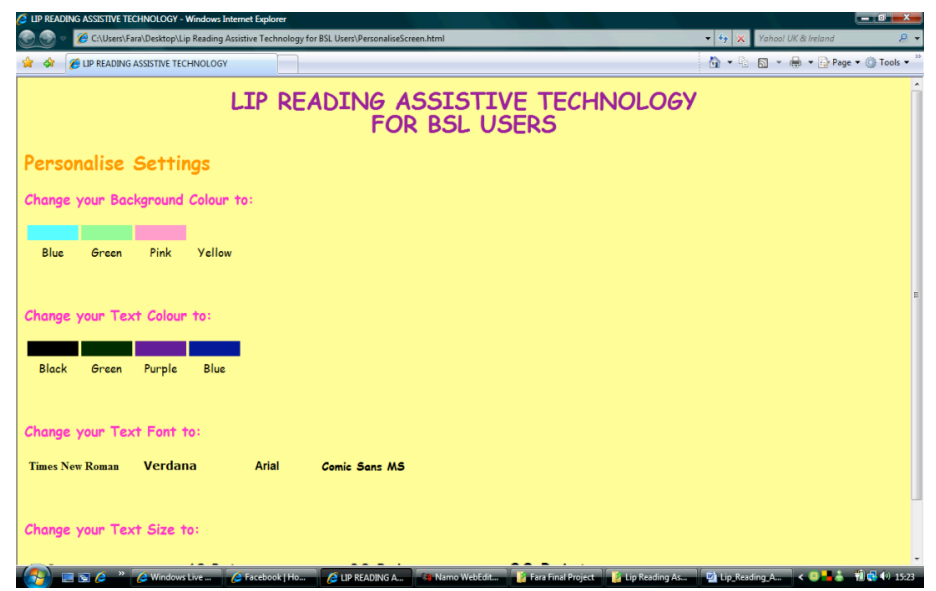

Fig. 2. - Personalise Settings Page

The interface was tested with these two participants, the results of the testing is given below both participants were able to use the developed interface is $100 \%$ success as the results show in Table 3

\begin{tabular}{|c|c|c|}
\hline Participant Number & $\begin{array}{c}\text { Learn Lip Reading } \\
\text { Through Alphabets }\end{array}$ & $\begin{array}{c}\text { Learn Lip Reading Through } \\
\text { Alphabets and BSL }\end{array}$ \\
\hline 1 & Yes & Yes \\
\hline 2 & Yes & Yes \\
\hline
\end{tabular}

Table 3. - Evaluation with deaf participants

\section{Conclusion}

Overall, the developed artefact 'Lip Reading Assistive Technology for BSL Users' was a success. This is because it not only met the specified requirements but also was an innovation for BSL users to learn Lip Reading. Being an innovation may also entail certain limitations as the users, especially the target audience, may be rather reluctant to use it initially. The fact that the BSL users who assisted in testing this artifact had to ask questions on how to use the artifact or pause to figure out how to use this artifact showed that there was further work to be done in this area of this research. However, their appreciation of the lip movements associated with BSL was promising. They had never encountered such a product before and yet found it rather interesting to use. 


\section{References}

1. RNID - http://www.rnid.org.uk/information_resources/aboutdeafness/causes/, retrieved on $10^{\text {th }}$ September 2007

2. Qi Wang, Xilin Chen, Liang-Guo Zhang, Chunli Wang and Wen Gao - Viewpoint invariant sign language recognition. Computer Vision and Image Understanding, Volume 108, Issues 1-2, October-November 2007, Pages 87-97, also available at OCG http://www.ogc.gov.uk/methods prince 2.asp, accessed on $14^{\text {th }}$ September 2007. Accessed on $15^{\text {th }}$ September 2007

3. Dafydd Waters, Ruth Campbell, Cheryl M. Capek, Bencie Woll, Anthony S. David, Philip K. McGuire, Michael J. Brammer and Mairéad MacSweeney - Fingerspelling, signed language, text and picture processing in deaf native signers: The role of the mid-fusiform gyrus NeuroImage, Volume 35, Issue 3, 15 April 2007, Pages 12871302, retrieved on $15^{\text {th }}$ September 2007

4. Yun-Long Lay, Chung-Ho Tsai, Hui-Jen Yang, Chern-Sheng Lin and Chuan-Zhao Lai - The application of extension neuro-network on computer-assisted lip-reading recognition for hearing impaired. Expert Systems with Applications, In Press,

5. Bauman, 2000, http://www.hearinglosshelp.com/articles/speechreading.htm, accessed on $12^{\text {th }}$ September 2007 